\title{
Results of Autogenous Vein Grafts in Repair of Major Arterial Injuries to the Upper and Lower Extremities with Reference to Wall Shear Stress
}

\author{
Li Zhao, M.D., F.I.C.A., ${ }^{1} *$ Yao-tian Huang, M.D., ${ }^{1} \mathrm{Jun} \mathrm{Li}^{2}{ }^{2}$ Min Huang, M.Sc. ${ }^{3}$ \\ ${ }^{1}$ Institute of Orthopaedic Surgery, Xijing Hospital, Xi' an, P.R. China; ${ }^{2}$ Department of Ultrasonography, Xijing Hospital, Xi'an, P.R. China; and \\ ${ }^{3}$ Department of Engineering Mechanics, Xi'an Jiaotong University, Xi'an, P.R. China
}

\begin{abstract}
This investigation was designed to retrospectively review the results of autogenous vein grafts used for extremity arterial injuries. The mean value of the wall shear stress during a cardiac cycle was calculated by blood flow waveform analysis. The records of 103 patients with 106 arterial injuries repaired with autogenous vein grafts were reviewed. One hundred and two $(96.2 \%)$ were patent in the early postoperative period. The mean length of follow-up was 6 years and 5 months (range 1-23 years). Fifty-one patients were followed beyond 1 year.

Of the 51 patients followed for more than 1 year, 49 (96.1\%) patients had excellent peripheral circulation, however, two patients complained of mild ischemic pain. The patency of 26 of the 28 vein grafts was revealed by Doppler ultrasonic imaging studies. The excellent results obtained in this investigation reinforced our preference for using autogenous vein grafts for repair of extremity arterial injuries. The upper extremity grafts had a better outcome than those of the lower extremity; this was associated with a higher value of the wall shear stress. We propose that wall shear stress be measured for follow-up studies of vascular grafts in extremity arterial injuries and that hemodynamic factors should be considered during arterial reconstructive procedures.
\end{abstract}

\section{Introduction}

The autogenous vein graft has been regarded as the most appropriate means for repairing selected arterial injuries of extremities [1-4], but unfortunately the long-term results are poorly described. Although a large number of investigations have been performed clinically and experimentally

\footnotetext{
*Visiting in Nuffield Department of Orthopaedic Surgery, University of Oxford, Headington, Oxford, England

Correspondence to: Li Zhao M.D., F.I.C.A., Nuffield Department of Orthopaedic Surgery, Headington, Oxford, OX3 7LD, England
}

concerning lower extremity arteriosclerosis [5-7], these results should not be applied to the situation of repair of arterial injuries. Late occlusion of the vein grafts may be caused by progressive arterial occlusive disease beyond the graft in addition to intimal hyperplasia within the graft. Therefore, we propose that it is necessary to investigate the long-term results of autogenous vein grafts in the repair of extremity arterial injuries.

Previous reports have outlined the clinical experiences regarding the treatment of extremity arterial injuries [1-4], focusing mainly on early patency of the vein graft. Operative manipulation and initial patency are variables at the onset of treatment. Excessive operative manipulation is thought to predispose to occlusion of the graft, and initial patency is correlated with the chance of salvage of the injured extremity. However, the hemodynamic effect of the interaction between blood flow and the vascular wall is present as long as the vein graft is in place. Studies of arterially transplanted vein grafts have revealed that intimal hyperplasia is a cause of stenosis and possible thrombosis in small to midsized arterial reconstructive procedures, and wall shear stress may be the essential hemodynamic factor in intimal hyperplasia $[5,6]$. Therefore, it would seem to be particularly useful to investigate the autogenous vein grafts in limbs without preexisting peripheral arterial disease. In the present study, we retrospectively reviewed the results of autogenous vein grafts in patients with arterial injuries to their upper and lower extremities with reference to mean value of the calculated wall shear stress during a cardiac cycle by blood flow waveform analysis.

\section{Materials and Methods}

\section{Patients}

Case records were studied for 103 patients with 106 extremity arterial injuries treated between 1963 and 1993 at the Institute of Orthopaedic 
Table 1. Distribution of arterial injuries

\begin{tabular}{lc}
\hline Artery & No. of vessels $(\%)$ \\
\hline Subclavian & $6(5.7)$ \\
Axillary & $6(5.7)$ \\
Brachial & $25(23.5)$ \\
Ulnar & $6(5.7)$ \\
Radial & $6(5.7)$ \\
External iliac & $4(3.8)$ \\
Femoral & $27(25.4)$ \\
Popliteal & $20(18.8)$ \\
Ant. tibial & $2(1.9)$ \\
Post. tibial & $4(3.8)$ \\
Total & $106(100.0)$ \\
\hline
\end{tabular}

Surgery, Xijing Hospital. There were 92 males and 11 females, aged 4-71 years; $69(66.9 \%)$ were between 20 and 50 years. In all, 35.9\% of patients had injuries caused by sharp objects, $19.4 \%$ by gunshot, and similar percentages by vehicles (13.6\%), machinery (10.7\%), and crush injuries (13.6\%). The brachial $(23.5 \%)$, femoral $(25.4 \%)$, and popliteal $(18.8 \%)$ arteries were frequently involved (Table 1).

A total of 77 patients (74.8\%) sustained acute arterial injuries and 26 were operated on for late injuries which were defined as initially untreated injuries or those treated more than 4 weeks after trauma, posttraumatic pseudoaneurysm, or arteriovenous fistula. Of the 77 patients with acute arterial injuries, $81.8 \%$ had associated nerve injuries, $77.9 \%$ had severe muscle injuries, $51.9 \%$ shock, $49.4 \%$ vein injuries, $41.6 \%$ fractures, and $7.8 \%$ dislocations. In addition, there were two patients with hemopneumothorax and two with abdominal visceral injuries.

Great saphenous vein grafts were used in $89.6 \%$ of patients. The length of the vein grafts ranged from 2 to $20 \mathrm{~cm}(2-5 \mathrm{~cm}$ in 24 grafts, $5-10 \mathrm{~cm}$ in 55 grafts, $10-20 \mathrm{~cm}$ in 17 grafts, and in eight cases the length was not recorded). The veins were usually excised from the opposite side, hydrostatically distended with heparinized saline solution, and reversed and interpositionally implanted into the arteries following complete debridement and primary treatment of the concomitant injuries. All efforts were made to provide adequate coverage of the repaired vessels, particularly with healthy muscle. One patient had a proximal end-to-side anastomosis, one was treated with an end-to-side subcutaneous bypass procedure, and two patients with vein patch repairs.

Follow-up information relevant to the evaluation of the early and late results of this treatment included extremity salvage, extremity function and circulation, and graft patency and durability which could be (1) directly observed due to reoperations upon nerve injuries, tendon injuries, and fractures; (2) demonstrated by arteriography; or (3) revealed by Dopplerultrasonic imaging studies with the employment of Hp-100 or Hp-1000 Doppler-ultrasonic image instrument $(7.5 \mathrm{HMz})$. The probe was located at the midportion of the vein graft. The internal diameter, mean flow velocity, and flow velocity waveform were measured and recorded on the video tape by a built-in video recorder. The heart rate was monitored by ECG throughout the hemodynamic measurement.

\section{Principle of Flow Waveform Analysis}

Under the assumption that (1) blood is a newtonian fluid and (2) the vessels being studied are tethered, straight, and elastic tubes, the wall shear stress could be calculated by the analysis of blood flow waveform, which could be obtained from the digitized B-mode screen velocity waveform multiplied by the cross-sectional area of the vessel being studied. The mean value of wall shear stress during a cardiac cycle, represented by $\tau$, is obtained by the following equation [8]:

$$
\tau=32 \mu \mathrm{Q} /\left(\pi \cdot \mathrm{D}^{3}\right)
$$

where $\mu^{\mathrm{m}}$ denotes the blood viscosity $\left(4.6 \times 10^{-3} \mathrm{~N} \cdot \mathrm{s} / \mathrm{m}^{2}\right)$, Q indicates the flow rate $(\mathrm{ml} / \mathrm{second})$, and $\mathrm{D}$ represents the internal diameter at the midportion of the graft $(\mathrm{cm})$.
Table 2. Number of cases for long-term follow-up studies

\begin{tabular}{lc}
\hline Duration (years) & No. of cases \\
\hline $1-3$ & 14 \\
$3-5$ & 8 \\
$5-8$ & 7 \\
$8-10$ & 5 \\
$>10$ & 17 \\
Total & 51 \\
\hline
\end{tabular}

\section{Statistical Analysis}

The data in this study were analyzed using analysis of variance followed by Student's $t$-test. A $p$ value of less than 0.05 was considered significant.

\section{Results}

\section{Graft Patency}

The patency was revealed in $102(96.2 \%)$ vein grafts during the early stage after operations. There were five $(4.7 \%)$ graft-related complications, including three thromboses, one graft infection, and one rupture at the proximal anastomosis. Seven patients had ischemic contractures due to injuries of six popliteal arteries and one femoral artery, respectively. Two of these seven patients underwent a delayed treatment of their arterial injuries. Six patients $(5.8 \%)$ required an amputation because of delay in diagnosis and management, massive soft tissue destruction, and renal failure due to myohemoglobinuria after revascularization. There were no deaths in this series.

Fifty-one patients were followed beyond 1 year after operations. The follow-up time ranged from 1 to 23 years with an average of 6 years and five months. The detailed duration for these cases is given in Table 2.

Forty-nine $(96.1 \%)$ patients had excellent peripheral circulation, but two complained of mild ischemic pain. Fortyone $(80.4 \%)$ patients had excellent extremity function. Ten patients $(19.6 \%)$ continued to be disabled due to incomplete nerve recovery. Follow-up data for the Doppler-ultrasonic imaging studies were available in 28 patients; 26 (92.9\%) of these 28 vein grafts were shown to be patent by Dopplerultrasonic imaging studies. The other two grafts in two patients were revealed to be occluded, yet neither of these patients had any ischemic pain. In one, arteriography demonstrated a large collateral circulation.

\section{Hemodynamic Studies}

Hemodynamic data by means of Doppler-ultrasonography were available for 22 cases. The time interval of the followup study ranged from 7 days to $12 \frac{1}{2} 2$ years after implantation of vein grafts. Fourteen of the 22 cases had had their vein grafts in place for more than 6 months (Fig. 1).

The mean value of wall shear stress was higher in the upper extremity group (over $1.1 \mathrm{~N} / \mathrm{m}^{2}$ ) than in the lower extremity group ( 5 over $1.1 \mathrm{~N} / \mathrm{m}^{2}$ and 7 below $1.1 \mathrm{~N} / \mathrm{m}^{2}$ ). No significant difference was found between the mean flow 


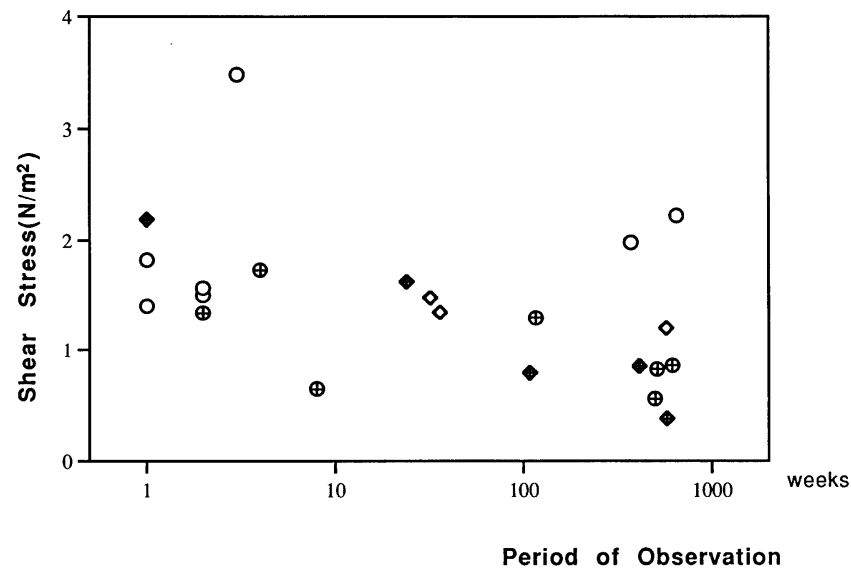

Fig. 1. Values of wall shear stress in vein grafts from 22 patients. $\diamond$, Subclavian A; ○, Brachial A; $\diamond$, Femoral A; $\oplus$, Popliteal A.

velocity values in upper and lower extremity groups (Table 3).

The mean value of wall shear stress of grafts with followup time of more than 24 weeks was over $1.1 \mathrm{~N} / \mathrm{m}^{2}$ in six grafts including one from the lower extremity, and the mean wall shear stress was below $1.1 \mathrm{~N} / \mathrm{m}^{2}$ in six grafts (all from lower extremities). The mean value of wall shear stress was lower beyond 24 weeks than within 24 weeks in the lower extremities. The mean value of wall shear stress was not significantly different within 24 weeks from that beyond 24 weeks in the upper extremities. No significant difference was found between the mean flow velocity values within and beyond 24 weeks postsurgery, either in upper or lower extremities.

\section{Discussion}

\section{Primary Management of Major Extremity Arterial Injuries}

Despite these clinical and numerous reports regarding arterial trauma, these injuries continue to be a common and challenging problem $[1-4,9]$. Successful treatment of major arterial injuries relates to extremity salvage and restoration of extremity function as well as prevention of death. Priority must be given to management of life-threatening injuries. Early diagnosis, prompt treatment, complete debridement, appropriate coverage of the repaired vessels, fasciotomy when indicated, and simultaneous treatment of concomitant injuries are crucial factors in successful extremity salvage and in maintaining patency of the repaired vessels.

The time factor is vitally important in the management of acute arterial injuries. Treatment should be as early as possible, preferably within 12 hours of injury. Of the 77 cases of acute arterial injuries, the 36 treated within 12 hours had better results (Table 5). The arterial injuries should be treated with particular reference to special locations. The literature reports a high amputation rate for injuries of the popliteal arteries [9]. The popliteal artery in one patient was completely transected with a comminuted fracture of the femur caused by a bullet wound. The patient was operated
Table 3. Data of mean wall shear stress $(\tau)$ and mean flow velocity

\begin{tabular}{llll}
\hline Location & No. & $\tau\left(\mathrm{N} / \mathrm{m}^{2}\right)$ & $\mathrm{V}_{\text {mean }}(\mathrm{cm} / \mathrm{sec})$ \\
\hline $\begin{array}{c}\text { Upper extremity } \\
\text { (subclavian A \& brachial A) }\end{array}$ & 10 & $1.79 \pm 0.67 *$ & $23.98 \pm 15.25$ \\
$\begin{array}{c}\text { Lower extremity } \\
\text { (femoral A \& popliteal A) }\end{array}$ & 12 & $1.09 \pm 0.55$ & $17.39 \pm 4.19$ \\
\hline
\end{tabular}

${ }^{*} p<0.05$, upper extremity vs lower extremity.

Table 4. Data of mean wall shear stress $(\tau)$ and mean flow velocity

\begin{tabular}{lllll}
\hline Time & No. & $\tau\left(\mathrm{N} / \mathrm{m}^{2}\right)$ & $\mathrm{V}_{\text {mean }}(\mathrm{cm} / \mathrm{sec})$ \\
\hline \multirow{2}{*}{$>24$ weeks } & Upper extremity & 5 & $1.95 \pm 0.87$ & $20.92 \pm 6.79$ \\
& Lower extremity & 5 & $1.51 \pm 0.57 *$ & $18.61 \pm 5.74$ \\
& Upper extremity & 5 & $1.64 \pm 0.44$ & $18.17 \pm 3.23$ \\
& Lower extremity & 7 & $0.79 \pm 0.28$ & $16.51 \pm 2.85$ \\
\hline
\end{tabular}

${ }^{*} p<0.05$, groups within 24 weeks vs beyond 24 weeks in the lower extremities.

Table 5. Time interval from injury to operation and outcome in patients with acute arterial injuries

\begin{tabular}{llll}
\hline $\begin{array}{l}\text { Time } \\
(\mathrm{hrs})\end{array}$ & $\begin{array}{l}\text { No. of } \\
\text { cases }\end{array}$ & $\begin{array}{l}\text { Amputation } \\
(\%)\end{array}$ & $\begin{array}{l}\text { Ischemic } \\
\text { contracture (\%) }\end{array}$ \\
\hline$<12$ & 36 & 0 & 2.7 \\
$>12$ & 41 & 12.2 & 12.2 \\
\hline
\end{tabular}

on 8 hours after injury. The popliteal artery was repaired with an autogenous vein graft, a fasciotomy was performed, and the femur fracture was managed by sliding traction. Eight-year follow-up showed excellent circulation and function of his involved leg with the vein graft patency documented by Doppler-ultrasonic image study.

Surgical intervention was indicated for late arterial injuries associated with severe ischemia, in this case a vascular graft was commonly required. In the management of pseudoaneurysm and arteriovenous fistula, excision of the lesion and restoration of vascular continuity should be performed as soon as possible after the wound has healed and the soft tissues are still soft. Waiting for collateral circulation to appear will jeopardize restoration of the circulation.

\section{Autogenous Vein Grafts for Reconstruction of Extremity Arteries}

Autogenous vein graft has been widely used to replace or bypass a medium or small-sized artery, for instance, in case a vascular conduit is required when there is extensive damage to the major extremity artery. It is well known that injury of the vascular wall, particularly endothelium which may be incurred during harvesting and preparation of autogenous vein graft, and grafting procedure probably lead to early graft failure, which may also be caused by lack of appropriate coverage and mismatch of luminal size between graft and host artery $[1-4,9,10]$. The autogenous vein undergoes intimal hyperplasia and medial thickening after implantation into the arterial circulation, and intimal hyperpla- 
sia has been implicated as one of the main causes of late graft failure [5,6].

Dilley et al. [11] developed a morphometric study of intimal hyperplasia in iliolumber veins grafted into iliac arteries of rats and found that the increase in mean thickness of the graft intima was most rapid from 2 to 21 days and then increased more gradually to reach a maximum at 140 days when the graft intima was the same thickness as the combined intima and media of the control artery [11]. In a similar model, McGeachie et al. [12] analyzed intimal hyperplasia histologically 8-18 months later and showed that the values did not significantly exceed the equivalent intimal plus medial thickness of control arteries. Dobrin et al. [13] performed the studies on dog femoral veins implanted into the femoral arteries and showed that intimal hyperplasia and medial thickening were separate responses to different stimuli. Results from experimental studies have revealed that change in wall shear stress is the essential hemodynamic factor related to intimal hyperplasia $[5,14,15]$. The results from our experimental study in a canine model revealed that the mean value of wall shear stress decreased dramatically at 1 hour after implantation, then increased and reached a fixed value beyond 1 week postsurgery [8]. Based on the findings of correlation between development of intimal hyperplasia and wall shear stress, lower wall shear stress at an early stage after implantation deserves careful attention. Okadome et al. [7] noted that late failure was more likely to occur in patients with reversed femoropopliteal vein grafts if they had a low shear stress variation. Follow-up examination is important for early recognition and treatment of graft failure. Lu et al. [16] found that the development of arterial collateral circulation took much more time than that of venous collateral circulation. Two patients with arterial injuries (one femoral and one popliteal, respectively) developed ischemic symptoms and contractures after the first grafting procedures. One of them required an orthopedic procedure to correct the contractures after the second revascularization operation for graft failure, which was diagnosed late. A gradual occlusion of repaired vessel may be supposed to allow the patient to develop good collateral flow and bring about successful extremity salvage, as described in this study.

\section{Outcome of Autogenous Vein Graft in Correlation with Wall Shear Stress}

The long-term results after vascular repair of injured extremity arteries with autogenous vein grafts have not been well defined. The predominant causes of late failure of these grafts is unknown. Okadome et al. [7] attempted to correlate the flow rate through the vein graft and shear stress variation of femoropopliteal autovein grafts with their outcome and found that shear stress variation rather than flow rate was closely correlated with the outcome of the vein grafts. Grafts with high shear stress variation showed good longterm results. In our study, occlusion of two grafts was documented in two patients, both involving the lower extremities (one femoral and one popliteal arteries), one of which was demonstrated by arteriography, showing a good collateral circulation. The mean value of wall shear stress was higher in upper than in lower extremities, especially when beyond 24 weeks after implantation. The mean value of wall shear stress was lower beyond 24 weeks than within 24 weeks in the lower extremity, but the similar finding was not shown in the upper extremity. No significant difference was found between the mean flow velocity values in upper and lower extremities, either within or beyond 24 weeks after implantations.

The importance of mechanical environment in determining the form and function of living tissues has long been recognized. Residual stress/strain has been found to exist in arteries and veins, and to play an important role in tissue remodeling. The zero-stress state, which can be described by the opening angle, is the simplest state of blood vessel and the initial state for mechanical analysis, and has been noted to vary with the locations of the vessels [17]. In a previous study, we evaluated the the postsurgical changes of the zero-stress state in canine vein grafts and found that the opening angle decreased dramatically in the early stage after implantation, then increased and tended to an asymptotic value comparable with veins [18]. Abbott et al. [19] stressed that mismatch in mechanical properties between host artery and graft led to graft failure. We recommend that more attention should be directed to the possible achievement of match in luminal size, mechanical properties of vascular wall, and hemodynamic characteristics which may vary with different locations. In a further study, it would be of interest to measure hemodynamic parameters with particular reference to wall shear stress during the perioperative period in the management of extremity arterial injuries.

\section{Conclusion}

The excellent results obtained in this study reinforce our preference for using autogenous vein grafts in the repair of extremity arterial injuries. A better outcome in upper rather than lower extremity vein grafts was found. This could be explained by the values of wall shear stress: the mean value of wall shear stress was higher in upper than in lower extremities, particularly after 24 weeks of implantation. We propose that wall shear stress be applied for follow-up studies of vascular grafts in extremity arterial injuries and that hemodynamic factors be considered for arterial reconstructive procedures.

Acknowledgment. This work was supported by a grant from Xijing Hospital. Professor Yupu Lu, who is deceased, was a pioneer in the research work of vein graft repair of extremity arterial injuries at the Institute of Orthopaedic Surgery, Xijing Hospital. We thank Ms. Jun Zhang for technical assistance with the ultrasonic examinations, and Mr. Hamish Simpson and Mr. Mark Emerton for their critical comments.

\section{References}

1. Keen RR, Meyer JP, Durhar JR, et al (1991) Autogenous vein grafts repair of injured extremity arteries: Early and late results with 134 consecutive patients. J Vasc Surg 13(5):664-668.

2. Lu YP, Li RS, Shi KJ, Xu LT (1980) Experimental studies on the development of arterial and venous collateral circulation after replantation of severed limbs. Chin Med J 93(5):331-334.

3. McCready RA, Logan NM, Daugherty ME, Mattingly SS, Crocker C, 
Hyde GL (1987) Long-term results with autogenous tissue repair of traumatic extremity vascular injuries. Ann Surg 206(6):804-808.

4. Mitchell FL, Thal ER (1990) Results of venous interposition grafts in arterial injuries. J Trauma 30(3):336-339.

5. Chervu A, Moore WS (1990) An overview of intimal hyperplasia. SGO 171:433-447.

6. Dilley RJ, McGeachie JK, Prendergast FJ (1988) A review of the histologic changes in vein-to-artery grafts, with particular reference to intimal hyperplasia. Arch Surg 123(6):691-696.

7. Okadome K, Yukizane T, Mii S, Fukuda A, Sugimachi K (1989) Correlation of long-term results of femoropopliteal autogenous vein grafts with shear stress variation/in situ or reversed graft? J Cardiovasc Surg (Torino) 30(6):932-935.

8. Huang M, Huang YT, Zhao L, Kuang ZB, Han HC, Li J (1993) Postsurgical changes of wall shear stress in canine vein grafts. In: Advances of Biomedical Engineering In China, Zhang ZS (ed). China University Press of Science and Technology. Hefei pp 297-300.

9. Martin LC, McKenney MG, et al (1994) Management of lower extremity arterial trauma. J Trauma 37(4):591-598.

10. Adcock OT, Adcock GLD, Wheeler JR, Gregory RT, Snyder SO, Gayle RG (1984) Optimal techniques for harvesting and preparation of reversed autogenous vein grafts for use as arterial substitutes: A review. Surgery 96(5):886-893.

11. Dilley RJ, McGeachie JK, Prendergast FJ (1986) A morphometric study of vein graft intimal hyperplasia. Plast Reconstr Surg 77(3):451454.
12. McGeachie JK, Meagher S, Prendergast FJ (1989) Vein-to-artery grafts: The long-term development of neo-intimal hyperplasia and its relationship to vasa vasorum and sympathetic innervation. Aust NZ J Surg 59:59-65.

13. Dobrin PB, Littooy FN, Golan J, Blakeman B, Fareed J (1988) Mechanical and histologic changes in canine vein grafts. J Surg Res 44:259-265.

14. Morinaga K, Okadome K, Kuroki M, Miyazaki T, Muto Y, Inokuchi K (1985) Effect of wall shear stress on intimal thickening of arterially transplanted autogenous veins in dogs. J Vasc Surg 2(3):430-433.

15. Okadome K, Yukizane T, Mii S, Sugimachi K (1990) Ultrastructural evidence of the effects of shear stress variation on intimal thickening in dogs with arterially transplanted autologous vein grafts. J Cardiovasc Surg (Torino) 31(6):719-726.

16. Lu YP, Huang YT, Zhao L, et al (1993) Management of major arterial injuries of limbs: A study of 166 cases. Cardiovasc Surg 1(5):486-488.

17. Liu SQ, Fung YC (1988) Zero-stress states of arteries. J Biomech Eng 110(1):82-84.

18. Zhao L, Huang YT, Han HC, et al (1993) Biomechanical and hemodynamic changes in autogenous vein grafts. Chinese J Repar Reconstruct Surg 7(2):91-94.

19. Abbott WM, Megerman J, Hasson JE, L'Italien G, Warnock DF (1987) Effect of compliance mismatch on vascular graft patency. J Vasc Surg 5(2):376-382. 